\title{
Strabismus Revealing Ciliary Body Medulloepithelioma: A Case Report and Literature Review
}

\author{
Widad Belaydi*, E. H. Abdallah, B. Marzouqi, A.Lalaoui, K. Amhoud, M.A. Filali, A. Berraho
}

Department of Ophtalmology, Ibn Sina Hospital, University Mohamed V, Rabat, Morocco

DOI: $10.36347 /$ sjams.2020.v08i09.013

| Received: 31.08.2020 | Accepted: 08.09.2020 | Published: 17.09.2020

*Corresponding author: Dr. BELAYDI Widad

Abstract

Ciliary body medulloepithelioma is rare congenital tumor. It develops from the non-pigmented ciliary body epithelium. It occurs mainly in the first decade of life. The clinical examination of the ciliary body is difficult that leads to a significant delay in diagnosis, until enlargement of the tumor, which produces secondary effects. The exact diagnosis is only made on histopathologic examination that found elements to differentiate between medulloepithelioma teratoid and non-teratoid, benign or malignant ones. Enucleation is the preferred method of treatment for advanced intraocular mass. Ciliary body medulloepithelioma have an excellent prognosis. The authors propose to describe a case of this rare tumor revealed by strabismus.

Keywords: Medulloepithelioma, ciliary body, strabismus, enucleation.

Copyright @ 2020: This is an open-access article distributed under the terms of the Creative Commons Attribution license which permits unrestricted use, distribution, and reproduction in any medium for non-commercial use (NonCommercial, or CC-BY-NC) provided the original author and source are credited.

\section{INTRODUCTION}

Medulloepithelioma is a rare congenital tumor of the ciliary body. It develops from the non-pigmented ciliary body epithelium [1]. It occurs mainly in children, but can rarely detect in adult [2]. Clinical signs vary and nonspecific, hence the diagnostic delay [3]. The diagnosis is mainly based on the histological examination, which distinguishes two types: nonteratoid medulloepithelioma and medulloepithelioma teratoid, which can be benign or malignant [4].

\section{ObSERVATION}

A 20-month-old girl, with strabismus of the left eye that appeared 3 months ago associated with red eye (Figure1). She had no pathological history, including no notion of eye trauma or fever. The ophtalmologic examination of the left eye found convergent strabismus with conjunctival hyperemia, a non-reactive pupil with 360 synechiae, and total cataract preventing visualization of the posterior pole, intraocular pressure was at $8 \mathrm{mmHg}$ (Figure 2).
The eye examination of the right eye did not show any abnormality. The general examination was normal.

The ocular ultrasound objectified a small eyeball with an intraocular hyperechoic process (Figure3). Computed tomography scan showed an intraocular mass, with heterogeneous enhancement, measuring $15 \times 12 \mathrm{~mm}$, irregular, dense, causing deformation of the eyeball, no calcifications were observed (Figure 4) .An inflammatory and infectious assessment (toxoplasmosis serology, toxocarosis, syphilis, lyme) were entirely normal. Radiological assessment of extraocular extension has returned to normal.

Due to age and intraocular tumor syndrome the diagnosis of retinoblastoma has not been completely ruled out. Enucleation was performed. The histological analysis revealed a Ciliary Body medulloepithelioma with Ki67 estimated at $2 \%$. The evolution was favorable without any local or general recurrence with a followup of 1 year (Figure 5). 


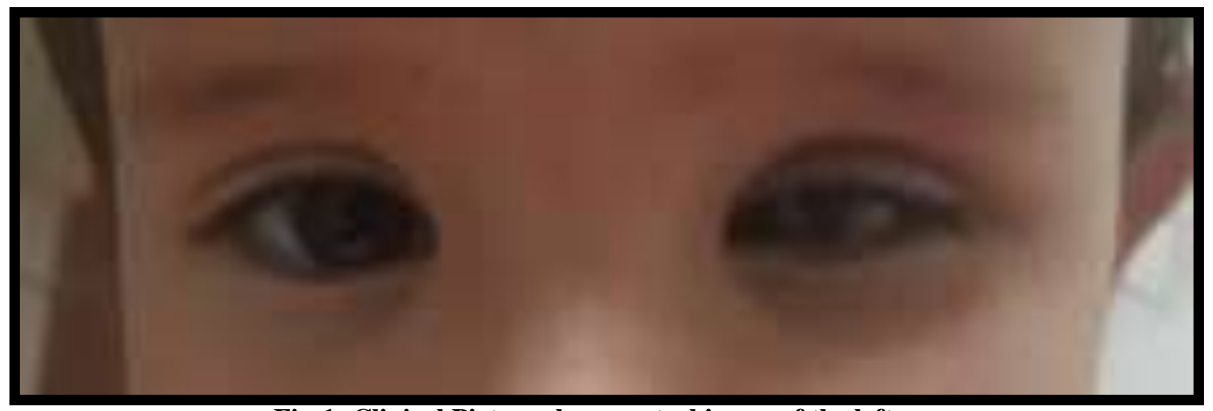

Fig-1: Clinical Picture shows a strabismus of the left eye

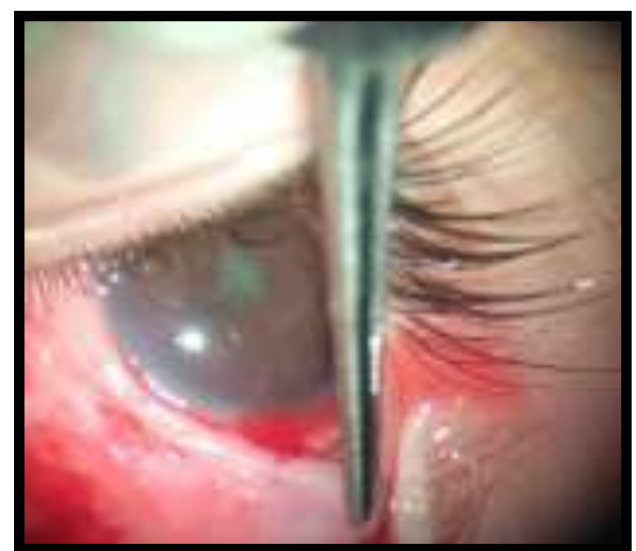

Fig-2: The ophtalmologic examination shows a non-reactive pupil with 360 synechiae, and total cataract

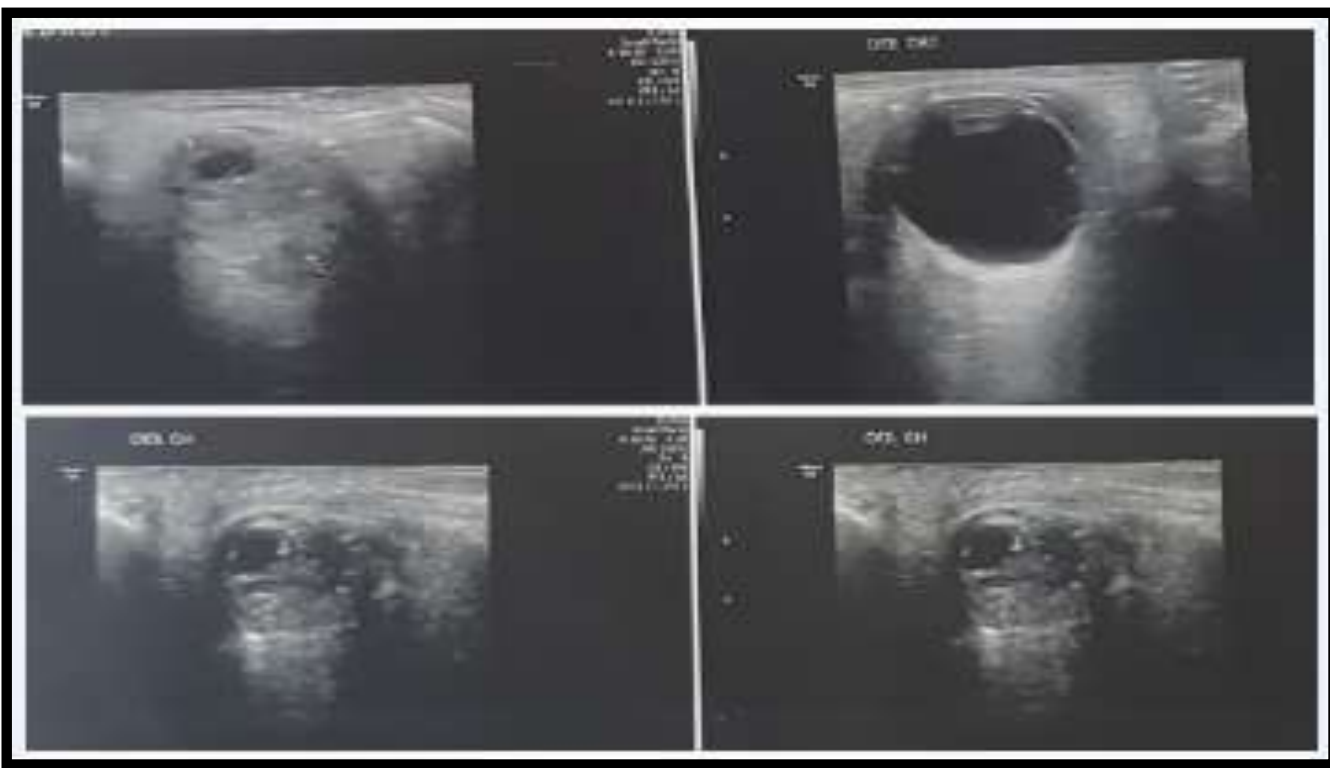

Fig-4: Ocular ultrasound objectified a small eyeball with an intraocular hyperechoic process

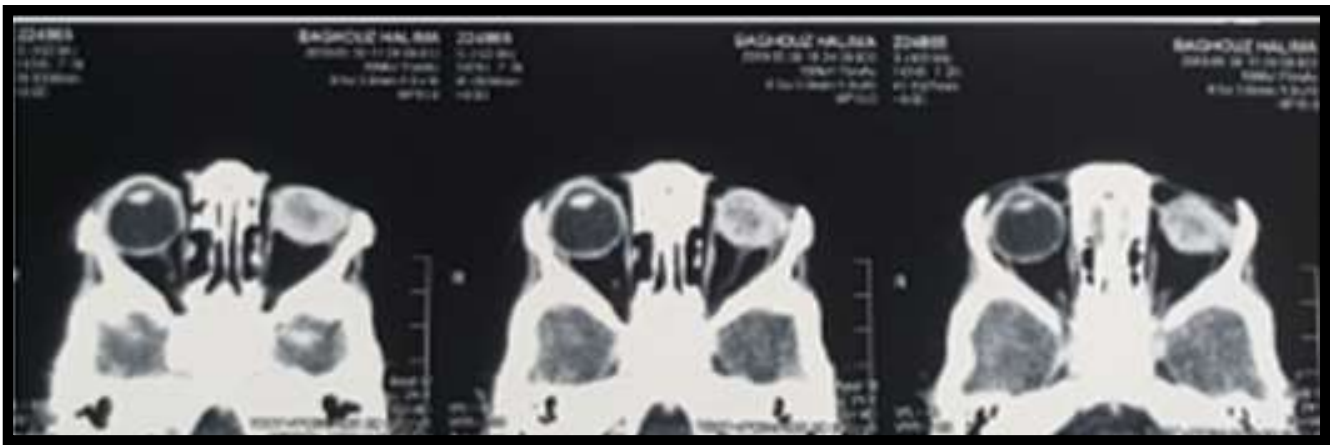

Fig-4: CT scan objectified an intraocular mass, causing deformation of the eyeball, with no calcifications 


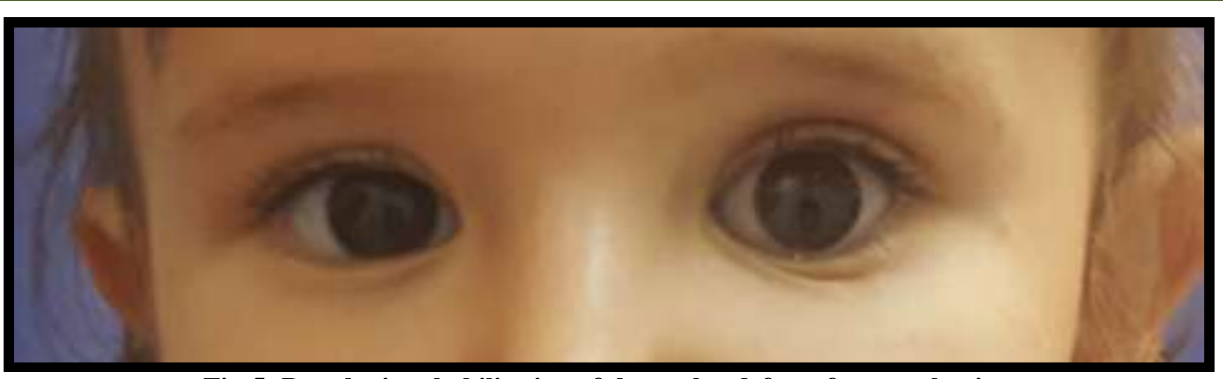

Fig-5: Prosthetic rehabilitation of the ocular defect after enucleation

\section{DiSCUSSION}

First report of medulloepithelioma was in 1892 by Badel and Lagrange, it was named carcinoma primitif [5]. Verhoeff coined the term of Teratoneuroma in 1904 due to the histologic detail of this uncommon tumor [6]. Later Fuchs in 1908 renamed it diktyoma [7]. The name of medulloepithelioma was proposed by Grinker in 1931 [8] considering the histological resemblance of the tumor to the neuroepithelium of the embryonic neural tube [9]. This was based on the work on a rarer form of medulloeptihelioma of the brain described by Bailey and Cushing [10, 11].

According to a large series by Broughton and Zimmerman [2], the median age at the time of initial clinical manifestation was 3.8 years. But, the median age at the time of surgery and histopathologic diagnosis was 5 years. The peak incidence occurs in the first decade of life .However, it may occasionally present in adults [12-14]. There is no predisposition, race, sex or inheritance $[2,15]$.

The difficulty in the direct visualizing of the ciliary body often delays the diagnosis of small tumors, until enlargement which produces secondary effects. The most common clinical presentation includes unilateral glaucoma and cataract with or without lens subluxation. In a study of 41 cases, glaucoma was present in $44 \%$ and cataract was present in $46 \%$ [15]. Which give the following symptoms: loss of vision, leukocoria, pain, or red eye. Other unusual presentations include strabismus [11].

On clinical examination, the mass of the ciliary body is usually appears irregular grey-white to pink [11]. Characteristic clear cysts can be evident in the mass on slit-lamp biomicroscopy in $60 \%$, such cysts can break free from the main tumor and float into the vitreous and aqueous [16]. It can rarely occur as a pigmented solid tumor [17]. The globe can be buphtalm or microphtalm [18]. Some vessels running the surface of the tumor can be shown. Other presentations include uveitis, hyphema, retinal detachment, vitreous hemorrhage, invasion of the optic nerve, and rarely extraocular extension of the tumor [11].
Ultrasound and computed tomography scan confirm the tumor diagnosis, but cannot differentiate neither between different tumors of the ciliary body nor with the anterior retinoblastoma. Magnetic resonance imaging eliminates non-tumor causes, in particular coats disease and persistent hyperplastic primary vitreous, the medulloepithelioma gives a T2 hypersignal and a T1 hyposignal. The exact diagnosis is only made on histopathological examination [3].

Histologically, medulloepithelioma is made up of elements which resemble the primitive medullary epithelium of the embryonic retina. The presence of heteroplastic elements helps to differentiate medulloepitheliomas teratoids and non-teratoid medulloepithelioma. Nonteratoid medulloepithelioma consists of a pure primitive medullary epithelium proliferation [19]. Whereas teratoid medulloepithelioma harbors heteroplastic elements, including hyaline cartilage, rhabdomyoblasts or striated muscle, or brainlike tissue in addition to the proliferation of the neuroepithelial elements. The criteria for malignancy include: [15].

- The presence of areas of poorly differentiated neuroblastic cells resembling those of retinoblastoma with or without rosettes

- Sarcomatous areas resembling chondrosarcoma, rhabdomyosarcoma, or embryonal sarcoma

- Nuclear pleomorphism, and high mitotic activity

- Invasion of the uvea, cornea, or sclera with or without extrascleral extension.

Management depends on the size of the tumor. The treatment options for small tumors include cryotherapy, local resection, plaque radiotherapy, external beam radiotherapy.

Local resection can be used for small circumscribed tumors, but it is reported to have up to $50 \%$ recurrence rate [15]. Enucleation is the preferred method of treatment for advanced intraocular medulloepithelioma with large tumors and neovascular glaucoma [11]. The role of systemic chemotherapy in the treatment of ciliary body medulloepithelioma is not well established [15]. Ciliary body medulloepithelioma have an excellent prognosis, with a 5-year survival of 90-95\% after enucleation, unless there is extraocular extension or central nervous system involvement [11]. 


\section{CONCLUSION}

The medulloepithelioma of ciliary body is a rare tumor, often diagnosed at an advanced stage of progression. Some clinical presentations in children should drive to a total eye examination especially the ciliar body, in order to enable an earlier detection and avoid the morbidity of enucleation.

\section{REFERENCES}

1. Agoston I. Sur les tumeurs épithéliales du corps ciliaire. Un cas de diktyome. Oncologia. 1966;20(2):84-98.

2. Broughton WL, Zimmerman LE. A clinicopathologic study of 56 cases of intraocular medulloepitheliomas. Am J Ophthalmol. 1978;85:407-18.

3. Charif chefchaouni M. Le médullo-épithéliome du corps ciliaire à propos d'un cas. J Fr Ophtalmol. 2000; 23(2): 165-169.

4. Campbell RJ, Sobin LH. Histological Typing of Tumours of the Eye and Its Adnexa, ed 2. Berlin, Springer, 1998.

5. Badel AJ, Lagrange F. Carcinome primitif de procès et du corps ciliare. Arch Ophthalmol (Paris). 1892; 12:143-8.

6. Verhoeff FH. A rare tumor arising from the pars ciliaris retinae (terato-neuroma) of a nature hitherto unrecognized, and its relation to the so-called glioma-retinae. Trans Am Ophthalmol Soc. 1904; 10(Pt 2):351-77.

7. Fuchs E. Growths and tumors of the ciliary epithelium [in German] Albrecht Von Graefes Arch Ophthalmol. 1908;68:534-87

8. Grinker RR. Gliomas of the retina including results of studies with silver impregnations. Arch Ophthalmol. 1931;5:920-35.

9. Verdijk RM. On the classification and grading of medulloepithelioma of the eye. Ocular oncology and pathology. 2016;2(3):190-3.
10. Bailey P, Cushing HW. A Classification of the Tumors of the Glioma Group on a Histo-genetic Basis, with a Correlated Study of Prognosis... With 108 Illustrations. JB Lippincott Company; 1926.

11. Tadepalli SH, Shields CL, Shields JA, Honavar SG. Intraocular medulloepithelioma-A review of clinical features, DICER 1 mutation, and management. Indian journal of ophthalmology. 2019 Jun;67(6):755.

12. Ali MJ, Honavar SG, Vemuganti GK. Ciliary body medulloepithelioma in an adult. Survey of ophthalmology. 2013 May 1;58(3):266-72.

13. Carrillo R, Streeten BW. Malignant teratoid medulloepithelioma in an adult. Archives of Ophthalmology. 1979 Apr 1;97(4):695-9.

14. Floyd BB, Minckler DS, Valentin L .Intraocular medulloepithelioma in a 79-year-old man. Ophthalmology. 1982 Sep; 89(9):1088-94.

15. Kaliki S, Shields CL, Eagle Jr RC, Vemuganti GK, Almeida A, Manjandavida FP, Mulay K, Honavar SG, Shields JA. Ciliary body medulloepithelioma: analysis of 41 cases. Ophthalmology. 2013 Dec $1 ; 120(12): 2552-9$.

16. Shields JA, Eagle Jr RC, Shields CL, De Potter P. Congenital neoplasms of the nonpigmented ciliary epithelium (medulloepithelioma). Ophthalmology. 1996 Dec 1;103(12):1998-2006.

17. Shields JA, Eagle RC, Shields CL, Singh AD, Robitaille J. Pigmented medulloepithelioma of the ciliary body. Archives of Ophthalmology. 2002 Feb $1 ; 120(2): 207-10$.

18. Reese AB. Tumors of the eye. Third edition. Harper and row, publishers hagerstown, maryland; 1976.

19. Charhi H, Harmouch A, Mansouri N, Maher M, Alami SI, Hajji Z, Berraho A, Sefiani S. Le médulloépithéliome du corps ciliaire: à propos de trois observations. Revue francophone des laboratoires. 2010;418(2010):73-5. 